\title{
ASSISTÊNCIA DE ENFERMAGEM À MULHER NO CLIMATÉRIO*
}

\author{
Carmem L. M. Candella** \\ Cintia Martins Ruggiero** \\ Marion E.S.Araya** \\ Rosilda Veríssimo Silva**
}

CANDELLA, C.L.M. Assistência de enfermagem à mulher no climatério. Rev.Esc.Enf.USP, v.29, n. 1, p.47-58, abr. 1995 .

O climatério é uma fase transitória que traz alterações significativas à vida da mulher. Este artigo enfatiza a importância da atuação do enfermeiro junto a essa clientela na promoção, proteção e recuperação da saúde. As autoras sugerem algumas orientações a serem dadas durante a prestação da assistência de enfermagem.

UNITERMOS: Assistência de Enfermagem. Climatério. Necessidades básicas afetadas. Saúde da mulher.

\section{INTRODUÇÃO}

Biologicamente, as mulheres na faixa etária dos 35 aos 65 anos, experimentam diversas alterações que afetam o seu equilíbrio biopsicossocial.

Estas alterações ocorrem devido a queda gradual dos hormônios ovarianos, estabelecendo assim, um desequilíbrio hipofise-gonadal.

Esta fase é chamada de climatério, que segundo SALTZ (1986), é o período terminal na biologia reprodutora da mulher em que os ovários, devido à diminuição da população folicular, elaboram menor quantidade de esteróides sexuais.

Aliados a esses fatores fisiológicos, as mulheres climatéricas vivenciam questões como: o envelhecimento, risco elevado de câncer, incidência de doenças crônicas, labilidade emocional, além de desconfortos experimentados em maior ou menor grau.

* Trabalho apresentado à disciplina Enfermagem Obstétrica e Neonatal

** Alunas do 6" semestre do Curso de Graduação da Escola de Enfermagem da USP 
O climatério é uma fase de transição que não ocorre de forma abrupta, iniciando-se em geral, aos 35 anos e ultimando-se aos 65 anos(ZIEGEL; CRANLEY, 1985 e Notelovitz apud ALDRIGHI, 1992).

Segundo Notelovitz apud ALDRIGHI (1992), esta fase está dividida em três estágios:

- estágio inicial ou precoce: dos 35 aos 45 anos;

- estágio médio: dos 46 aos 55 anos;

- estágio tardio: dos 56 aos 65 anos.

Em geral, no estágio médio ocorre um evento muito importante, que é a menopausa, a qual segundo alguns autores, é definida apos doze meses da cessação das menstruações, ou ainda, quando cirurgicamente induzida. Após a confirmação, a menopausa é classificada nos dois primeiros anos como mediata, e nos anos subseqüentes como tardia (GRANT, 1990 e DE LUCA, 1993).

Popularmente, o termo menopausa é utilizado de maneira incorreta para definir as alterações psíquicas e biológicas características do climatério.

Os sinais e sintomas freqüentemente observados durante o climatério, devem-se às alterações ocorridas nos sistemas nervoso, circulatório, endócrino e urinário.

A seguir, apresentamos o Quadro 1 que contém as principais alterações orgânicas e suas respectivas manifestações clínicas.

QUADRO 1 - Alterações orgânicas e manifestações clínicas observadas durante o climatério.

\begin{tabular}{|c|l|l|}
\hline SISTEMA & \multicolumn{1}{|c|}{$\begin{array}{c}\text { ALTERAÇÕES } \\
\text { ORGÂNICAS }\end{array}$} & MANIFESTAÇÕES CLÍNICAS \\
\hline Nervoso & $\begin{array}{l}\text { Redução da concentração } \\
\text { de monoamina, devido à } \\
\text { queda de hormônios } \\
\text { esteróides. }\end{array}$ & $\begin{array}{l}\text { Ansiedade, nervosismo ou } \\
\text { irritabilidade, insônia, fadiga ou } \\
\text { sonolência por } \\
\text { hiperexcitabilidade, depressão, } \\
\text { labilidade afetiva. }\end{array}$ \\
$\begin{array}{l}\text { Redução da produção de } \\
\text { endorfinas que } \\
\text { desequilibra as funções do } \\
\text { centro termorregulador, } \\
\text { provocando a dilatação } \\
\text { dos vasos sangüíneos. }\end{array}$ & Fogachos (ondas de calor). \\
\hline
\end{tabular}


QUADRO 1 - Alterações orgânicas e manifestações clínicas observadas durante o climatério.

\begin{tabular}{|c|c|c|}
\hline SISTEMA & $\begin{array}{l}\text { ALTERAÇÕES } \\
\text { ORGÂNICAS }\end{array}$ & MANIFESTAÇÕES CLÍNICAS \\
\hline Circulatório & $\begin{array}{l}\text { Redução da luz dos vasos } \\
\text { sangüíneos, devido a } \\
\text { aterosclerose que diminui } \\
\text { a oxigenação das artérias } \\
\text { cerebrais. } \\
\text { Elevação das taxas de } \\
\text { colesterol e triglicérides, } \\
\text { correlacionada ao risco de } \\
\text { doença cardiovascular. }\end{array}$ & Doença isquêmica coronariana. \\
\hline Reprodutor & $\begin{array}{l}\text { Diminuição da população } \\
\text { folicular que reduz a } \\
\text { produção de hormônios } \\
\text { esteróides. }\end{array}$ & $\begin{array}{l}\text { Irregularidades menstruais, } \\
\text { vaginites, dispareunias, distrofia } \\
\text { dos tecido estrôgenio } \\
\text { dependentes, diminuição da } \\
\text { capacidade reprodutora. }\end{array}$ \\
\hline Ósseo & $\begin{array}{l}\text { Redução da massa óssea, } \\
\text { devido ao aumento da } \\
\text { reabsorção óssea levando } \\
\text { à osteoporose. }\end{array}$ & Fraturas ósseas. \\
\hline Urinário & Atrofia da bexiga e uretra. & $\begin{array}{l}\text { Urgência urinária, incontinência } \\
\text { de esforço, cistite. }\end{array}$ \\
\hline
\end{tabular}

Fonte: Halbe(1987), De Luca (1993) 
Goodman apud GRANT (1990), estudou um grupo de mulheres Agta, nas Filipinas, e observou que estas não referem lembranças sobre sintomas físicos ou psicológicos durante o climatério e ou associados à menopausa, e ainda que, não existe termo lingüístico para demonstrar este evento.

Entre as mulheres de Rajasthan, na India, também não há relato de qualquer sintomatologia associada ao climatério, porém elas referem alta expectativa de serem menopausadas. Flint apud GRANT (1990), explora a possibilidade de que tal expectativa se deva ao fato de que, nesta cultura, às mulheres pós-menopausadas é permitido saírem do lugar onde vivem e beberem com os homens num contraste com os costumes anteriores à menopausa.

Para algumas mulheres, as alterações orgânicas e manifestações clínicas que surgem no climatério, são acompanhadas de sentimentos relacionados ao temor da perda da juventude e aumento de gastos com a saúde.

Nas culturas norte-americana e brasileira, o climatério 6 relatado pelas mulheres como um período de desconfortos em graus variados. Sabe-se que esses povos cultuam a juventude e aspectos a ela interligados, tais como a beleza, aparência física etc, o que se contrapõe à concepção de climatério, que para essas mulheres é uma fase associada à velhice, e no Brasil os idosos ainda são indivíduos rejeitados e considerados como improdutivos economicamente.

Este quadro nos leva a crer que esta inquietude faz com que as mulheres brasileiras vivenciem o climatério como uma fase marcante de suas vidas.

Observa-se hoje um aumento de expectativa de vida das mulheres brasileiras, nesse sentido, há umà elevação do número de mulheres vivenciando o climatério, requerendo portanto dos serviços da saúde melhor preparo dos profissionais que prestam assistência a essa clientela bem como uma busca constante de novas práticas diagnósticas e terapêuticas que propiciem uma melhora no quadro de sintomas apresentado pelas mulheres climatéricas.

Para uma assistência integral e de qualidade faz-se necessário que uma equipe multiprofissional composta de enfermeiro, médico, fisioterapeuta, terapeuta ocupacional, psicologo e nutricionista, atue conjuntamente no atendimento a essas mulheres, de maneira global, considerando que elas não trazem uma simples "queixa", mas considerando sua história de vida dentro de um contexto social.

Dentro da prática assistencial do enfermeiro, destacamos a consulta de enfermagem como uma estratégia para identificar as necessidades básicas afetadas de sua cliente e, a partir das informações coletadas, planejar e implementar medidas de enfermagem visando a promoção da saúde, proteção, recuperação ou reabilitação das mulheres climatéricas.

Ressaltamos ainda, a importância dessa assistência ser extensiva aos familiares que convivem com estas mulheres, pois esta conduta facilita o 
trabalho da equipe na busca da recuperação do equilíbrio biopsicossocial da cliente.

Com base na literatura e nas observações feitas durante o ensino te6rico prático, no curso de graduação cm enfermagem, em um serviço de atendimento à mulher climatérica, elaboramos um quadro que apresentamos a seguir.

No Quadro 2 listamos as necessidades básicas afetadas nas mulheres climatéricas, as orientações adequadas e as justificativas para esta conduta que têm como objetivo, minimizar a sintomatologia do climatério e até mesmo prevenir a instalação de patologias comuns nesta fase.

QUADRO 2 - Assistência de enfermagem à mulher climatérica: necessidades básicas afetadas, orientações e justificativas. São Paulo, 1994.

\begin{tabular}{|c|l|l|}
\hline $\begin{array}{c}\text { NECESSIDADES } \\
\text { BÁSICAS } \\
\text { AFETADAS }\end{array}$ & ORIENTAÇÕES & \multicolumn{1}{|c|}{ JUSTIFICATIVAS } \\
\hline $\begin{array}{c}\text { Ajustamento } \\
\text { Social }\end{array}$ & $\begin{array}{l}\text { Buscar alguma } \\
\text { atividade remunerada } \\
\text { ou não, escolher um } \\
\text { "hobby", participar de } \\
\text { reuniões de entidades } \\
\text { filantrópicas, } \\
\text { participar de } \\
\text { excursões. }\end{array}$ & $\begin{array}{l}\text { Opanço da idade, a } \\
\text { aposentadoria, a licença médica } \\
\text { do trabalho e outras causas que } \\
\text { impedem uma atividade } \\
\text { econômica, acabam por } \\
\text { desencadear sentimentos } \\
\text { relacionados à incapacidade e } \\
\text { inutilidade à sociedade. O } \\
\text { retorno ao trabalho ou a outras } \\
\text { atividades, melhora o } \\
\text { relacionamento afetivo, a } \\
\text { auto-estima a independência } \\
\text { financeira, a comunicação, o } \\
\text { status, etc. }\end{array}$ \\
$\begin{array}{c}\text { Sistema } \\
\text { articular, ósseo, } \\
\text { muscular e } \\
\text { circulatório. }\end{array}$ & $\begin{array}{l}\text { Fazer exercícios com } \\
\text { peso halteres; } \\
\text { Fazer exercícios de } \\
\text { bicicletas com as } \\
\text { pernas; }\end{array}$ & $\begin{array}{l}\text { Diminuir a vida sedentária e } \\
\text { promover a resistência } \\
\text { muscular e cardio-respiratória. }\end{array}$ \\
\hline
\end{tabular}


QUADRO 2 - Assistência de enfermagem à mulher climatérica: necessidades básicas afetadas, orientações e justificativas. São Paulo, 1994.

\begin{tabular}{|c|l|l|}
\hline $\begin{array}{c}\text { NECESSIDADES } \\
\text { BÁSICAS } \\
\text { AFETADAS }\end{array}$ & \multicolumn{1}{|c|}{ ORIENTAÇÕES } & \\
\hline $\begin{array}{c}\text { Sistema } \\
\text { articular, ósseo, } \\
\text { muscular e } \\
\text { circulatório. }\end{array}$ & $\begin{array}{l}\text { Reservar um horário } \\
\text { para caminhadas de } \\
\text { preferência, em } \\
\text { horários de sol } \\
\text { terapêutico (entre 8 e } \\
\text { 10 horas e a partir das } \\
\text { 16 horas), em local } \\
\text { arborizado e de } \\
\text { maneira gradual (5 } \\
\text { minutos no primeiro } \\
\text { dia, 10 minutos no } \\
\text { segundo dia e assim } \\
\text { por diante); }\end{array}$ & $\begin{array}{l}\text { Propiciar uma melhor absorção } \\
\text { da vitamina D; }\end{array}$ \\
$\begin{array}{l}\text { Ingerir alimentos ricos } \\
\text { em cálcio, como leite e } \\
\text { queijos, evitando o café } \\
\text { a fim de não prejudicar } \\
\text { sua absorção; }\end{array}$ & $\begin{array}{l}\text { Prevenir a osteoporose. } \\
\text { Apoiar as pernas em } \\
\text { banquetas quando } \\
\text { estiver executando } \\
\text { atividades na posição } \\
\text { sentada; }\end{array}$ & $\begin{array}{l}\text { Facilitar o retorno venoso, pois o } \\
\text { sistema circulatório está com } \\
\text { alterações como a trombose de } \\
\text { membros inferiores, o que } \\
\text { dificulta o retorno venoso. }\end{array}$ \\
$\begin{array}{l}\text { Apoiar os pés } \\
\text { alternadamente quando } \\
\text { estiver executando } \\
\text { atividades da vida } \\
\text { diária (lavar, passar } \\
\text { roupa, cozinhar, etc). }\end{array}$ & $\begin{array}{l}\text { Permitir a alteração da mudança } \\
\text { de apoio e descanso do membro. }\end{array}$ \\
\hline
\end{tabular}


QUADRO 2 - Assistência de enfermagem à mulher climatérica: necessidades básicas afetadas, orientações e justificativas. São Paulo, 1994.

\begin{tabular}{|c|c|c|}
\hline $\begin{array}{c}\text { NECESSIDADES } \\
\text { BÁSICAS } \\
\text { AFETADAS }\end{array}$ & ORIENTAÇÕES & JUSTIFICATIVAS \\
\hline $\begin{array}{c}\text { Sistema } \\
\text { articular, ósseo, } \\
\text { muscular e } \\
\text { circulatório. }\end{array}$ & $\begin{array}{l}\text { Observar o que } \\
\text { melhora os fogachos; } \\
\text { evitar o fumo; }\end{array}$ & $\begin{array}{l}\text { Buscar alivio e conforto; cada } \\
\text { mulher, com o tempo começa a } \\
\text { perceber o que pode melhorar } \\
\text { os fogachos, mas para isto ela } \\
\text { mesma tem que começar a se } \\
\text { conhecer, e conhecer como } \\
\text { funciona seu organismo. } \\
\text { Prevenir as doenças } \\
\text { cardio-respiratorias, } \\
\text { principalmente quando a } \\
\text { mulher faz uso de } \\
\text { contraceptivos. }\end{array}$ \\
\hline Sono e Repouso & $\begin{array}{l}\text { Reservar, na medida } \\
\text { do possível, um } \\
\text { horário para repousar; } \\
\text { Evitar a ingestão de } \\
\text { bebida ou drogas } \\
\text { estimulantes à noite; }\end{array}$ & $\begin{array}{l}\text { Repor o sono e descansar, } \\
\text { melhorando a disposição para o } \\
\text { desempenho das atividades, } \\
\text { pois a depressão sentida pelas } \\
\text { mulheres climatéricas } \\
\text { levam-na a ter dificuldade de } \\
\text { conciliar o sono. } \\
\text { Propiciar o repouso e períodos } \\
\text { mais longos de sono, uma vez } \\
\text { que um dos efeitos indesejáveis } \\
\text { dos barbitúricos o o efeito } \\
\text { rebote, deixando o indivíduo } \\
\text { excitado dificultando que } \\
\text { adormeça ou tenha periodos } \\
\text { mais curtos de sono. }\end{array}$ \\
\hline
\end{tabular}


QUADRO 2 - Assistência de enfermagem à mulher climatérica: necessidades básicas afetadas, orientações e justificativas. São Paulo, 1994.

\begin{tabular}{|c|c|c|}
\hline $\begin{array}{c}\text { NECESSIDADES } \\
\text { BÁSICAS } \\
\text { AFETADAS }\end{array}$ & ORIENTAÇÕES & JUSTIFICATIVAS \\
\hline $\begin{array}{c}\text { Equilibrio } \\
\text { hídrico e } \\
\text { nutricional }\end{array}$ & $\begin{array}{l}\text { Orientar a dieta para } \\
\text { o controle da } \\
\text { obesidade; } \\
\text { Controlar os níveis } \\
\text { séricos de colesterol, } \\
\text { glicose e cálcio; } \\
\text { Diminuir a ingesta de } \\
\text { alimentos com altos } \\
\text { níveis de sal e açúcar } \\
\text { refinados, bem como } \\
\text { massas e } \\
\text { refrigerantes; } \\
\text { Ingerir alimentos com } \\
\text { fibras, cálcio, } \\
\text { vitaminas e ferro; }\end{array}$ & $\begin{array}{l}\text { Evitar as micções freqüentes } \\
\text { durante a madrugada que } \\
\text { promovem um sono } \\
\text { descontinuado. } \\
\text { Prevenir a obesidade, } \\
\text { osteoporose e outras patologias } \\
\text { associadas a distúrbios } \\
\text { nutricionais, bem como a } \\
\text { prática abusiva de alimentos } \\
\text { com altos níveis de colesterol e } \\
\text { sacarose. } \\
\text { áre } \\
\text { Impedir a instalação de } \\
\text { problemas obstrutivos, } \\
\text { hipovitaminose e anemia. }\end{array}$ \\
\hline
\end{tabular}


QUADRO 2 - Assistência de enfermagem à mulher climatérica: necessidades básicas afetadas, orientações e justificativas. São Paulo, 1994.

\begin{tabular}{|c|c|c|}
\hline $\begin{array}{c}\text { NECESSIDADES } \\
\text { BÁSICAS } \\
\text { AFETADAS }\end{array}$ & ORIENTAÇÕES & JUSTIFICATIVAS \\
\hline $\begin{array}{c}\text { Equilibrio } \\
\text { hídrico e } \\
\text { nutricional }\end{array}$ & $\begin{array}{l}\text { Caminhar após as } \\
\text { refeições; } \\
\text { Aumentar a ingesta } \\
\text { hídrica durante o dia. }\end{array}$ & $\begin{array}{l}\text { Prevenir a dependência } \\
\text { alcob́lica dquelas pessoas que } \\
\text { buscam no álcool a solução dos } \\
\text { problemas, da depressão e } \\
\text { ansiedade. } \\
\text { Evitar a sensação de } \\
\text { "empachamento". } \\
\text { Propiciar um melhor } \\
\text { funcionamento de orgãos como } \\
\text { rins e intestinos. }\end{array}$ \\
\hline Memória & $\begin{array}{l}\text { Fazer palavras } \\
\text { cruzadas, ler trechos } \\
\text { de livros e tentar } \\
\text { lembrar o que foi lido, } \\
\text { treinar seqüência } \\
\text { logica com jogos de } \\
\text { memória. }\end{array}$ & $\begin{array}{l}\text { Promover a realização de } \\
\text { atividades e raciocínio,pois é } \\
\text { comum nesta fase da vida as } \\
\text { deficiências de memoria, e o } \\
\text { treino constante leva a uma } \\
\text { melhora significativa devido ao } \\
\text { aumento de irrigação cerebral. } \\
\text { (GUYTON, 1986) }\end{array}$ \\
\hline Reprodução & $\begin{array}{l}\text { Orientar na escolha } \\
\text { mais apropriada de } \\
\text { métodos } \\
\text { contraceptivos. }\end{array}$ & $\begin{array}{l}\text { Evitar a ocorrência de uma } \\
\text { gravidez indesejada ou de risco, } \\
\text { pois as mulheres climatéricas } \\
\text { não menopausadas têm a } \\
\text { função reprodutora apenas } \\
\text { diminuida e não nula. }\end{array}$ \\
\hline & $\begin{array}{l}\text { Orientar como deve } \\
\text { ser feita a higiene dos } \\
\text { genitais. } \\
\text { Evitar o uso de } \\
\text { duchas vaginais. }\end{array}$ & $\begin{array}{l}\text { Prevenir a proliferação de } \\
\text { agentes infecciosos e a } \\
\text { instalação de patologias } \\
\text { ginecologicas e suas } \\
\text { conseqüências. }\end{array}$ \\
\hline
\end{tabular}


QUADRO 2 - Assistência de enfermagem à mulher climatérica: necessidades básicas afetadas, orientações e justificativas. São Paulo, 1994.

\begin{tabular}{|c|c|c|}
\hline $\begin{array}{c}\text { NECESSIDADES } \\
\text { BÁSICAS } \\
\text { AFETADAS }\end{array}$ & ORIENTAÇÕES & JUSTIFICATIVAS \\
\hline Reprodução & $\begin{array}{l}\text { Trocar os absorventes } \\
\text { a cada } 3 \text { ou } 4 \text { horas, } \\
\text { principalmente } \\
\text { aqueles de uso } \\
\text { interno. } \\
\text { Orientar para a } \\
\text { prevenção de doenças } \\
\text { sexualmente } \\
\text { transmissíveis. } \\
\text { Orientar como deve-se } \\
\text { proceder para a } \\
\text { realização do auto } \\
\text { exame das mamas. } \\
\text { Orientar a mulher } \\
\text { sobre a necessidade da } \\
\text { freqüência das visitas } \\
\text { ao ginecologista. } \\
\text { Orientar para o } \\
\text { preparo adequado nas } \\
48 \text { horas que } \\
\text { precedem o exame de } \\
\text { colpocitologia } \\
\text { oncologica. }\end{array}$ & $\begin{array}{l}\text { Evitar o aparecimento de } \\
\text { patologias que facilitem a } \\
\text { ocorrência de doenças } \\
\text { ginecologicas e suas } \\
\text { conseqüências. } \\
\text { Detectar precocemente as } \\
\text { patologias que acometem as } \\
\text { mamas. } \\
\text { Prevenir e diagnosticar } \\
\text { precocemente o câncer } \\
\text { ginecologico através de exame } \\
\text { de colpocitologia oncologica. } \\
\text { Evitar o falseamento dos } \\
\text { resultados. }\end{array}$ \\
\hline
\end{tabular}

\section{CONCLUSÕES/CONSIDERAÇÕES FINAIS}

O climatério é uma nova etapa da vida das mulheres que tem diversos significados, que variam de mulher para mulher, em função da sua própria história de vida. 
Os serviços de atendimento à saúde da mulher, devem ter uma proposta visando uma melhor qualidade de vida das mulheres climatéricas.

Cabe ao enfermeiro, como integrante de uma equipe multidisciplinar, atuar junto à essas mulheres, considerando que este elemento tem embasamento teórico prático necessário para possibilitar o desenvolvimento de suas ações.

Este estudo traz uma proposta de orientações a serem dadas às mulheres durante a consulta de enfermagem ou para grupos que possbilitem a troca de vivências.

O desenvolvimento da consulta de enfermagem ocorre conforme as necessidades encontradas no momento que ela está acontecendo, ou seja, serão dadas as orientações à medida que haja necessidade daquela informação. $O$ exposto acima tem sua validade no direcionamento, cabendo ao enfermeiro detectar as prioridades de cada momento, para que não haja repetições desnecessárias a cada retorno para consulta.

Na consulta de enfermagem serão dados esclarecimentos também, acerca das modificações orgânicas, da sintomatologia e outras informações que se façam necessárias.

Gostariamos de ressaltar que as orientações são dadas objetivando uma melhoria na qualidade de vida das mulheres climatéricas, mas, sem dúvida, associada a essa prática quando indicada e com acompanhamento médico, a terapia de reposição hormonal melhora significativamente a sintomatologia apresentada por essas mulheres, que devem ser esclarecidas quanto às vantagens e benefícios, bem como os possiveis riscos desta terapia (RENOVAÇ. Â , 1991).

Lembramos que a assistência de enfermagem, quando possível, realizada fora do ambiente hospitalar, como por exemplo, na visita domiciliária, leva a uma desassociação do climatério como doença e que esta assistência pode se estender a todos que convivem com a mulher climatérica, o que, colaboraria para o sucesso desta prática assistencial, culminando com uma satisfação do profissional enfermeiro.

CANDELLA, C.I.M. et al. Nursing care for climateric women. Rev.Esc.Enf.USP, v.29, n. 1, p.4758, Apr. 1995.

Climateric is a transitory stage in women's life, which causes remarkable alterations. This article brings into focus how important the nurse performance is, giving protection, promotion and recuperation for women's health. The authors sugest some recomendations during nursing care.

UNITERMS: Climaterium. Nursing care. Basic necessities affected Women's health. 


\section{REFERÊNCIA BIBLIOGRÁFICA}

ALDRIGHI, J.M. Anticoncepção no climatério. Femina, v. 20, n. 4, p. 274-91, 1992.

AMBER, R. Cromoterapia: a cura através das cores. São Paulo, Cultrix, 1983.

DE LUCA, R. et al. Saúde e bem-estar: quando a menopausa chegar. São Paulo, CLR Balieiro, 1993.

GRANT, W.H. Climatério: tempo de mudança. São Paulo, 1990. 225 p. Tese (Doutorado) Instituto de psicologia, Universidade de São Paulo.

GUYTON, A.C. Fisiologia humana e mecanismos das doenças. Rio de Janeiro, Guanabara, 1986.

HALBE, H.W. Tratado de ginecologia. São Paulo, Roca, 1987. v.2. cap. 70, p. 923-32:

Climatério compensado.

HALBE, H.W. Tratado de ginecologia. São Paulo, Roca, 1987. v.2. cap. 71, p. 933-58:

Climatério descompensado.

RENOVAÇÃO TERAPÉUTICA PARA O ClimATÉRIO. J.Climatério, São Paulo, v.1, n.2, p. 6-7, 1991.

SALTZ, E. et al. Fichário clínico terapêutico. São Paulo, Mason do Brasil: 1986.

ZIEGEL, E.E.; CRANLEY, M.S. Enfermagem obstétrica. Rio de Janeiro, Guanabara, 1985. p. 7-28: Anatomia e fisiologia dos órgãos reprodutores. 